\title{
Demographics and follow up of post partum intra-uterine copper device in tertiary hospital in Delhi, India
}

\author{
Nidhi Garg ${ }^{1 *}$, Bani Sarkar ${ }^{1}$, Saloni Singla ${ }^{1}$, Rajesh Kumar Meena ${ }^{2}$
}

\begin{abstract}
${ }^{1}$ Department of Obstetrics and Gynecology, Dr. Ram Manohar Lohia Hospital, New Delhi, India
${ }^{2}$ Department of Medicine, Lady Hardinge Medical College, New Delhi, India
\end{abstract}

Received: 24 February 2019

Accepted: 04 May 2019

\section{*Correspondence:}

Dr. Nidhi Garg,

E-mail: dr.gargnidhi@gmail.com

Copyright: (C) the author(s), publisher and licensee Medip Academy. This is an open-access article distributed under the terms of the Creative Commons Attribution Non-Commercial License, which permits unrestricted non-commercial use, distribution, and reproduction in any medium, provided the original work is properly cited.

\begin{abstract}
Background: Increasing unintended pregnancies in post partum females in our country warrants urgent attention towards prevalence and efficacy of contraceptives used. This study was done to determine the prevalence of PPIUCD and its follow up in patients attending tertiary hospital in New Delhi, India.

Methods: Prospective study was carried in Department of Obstetrics and Gynecology, Dr. RML Hospital, New Delhi, India over a period of 1 year from July 2017 to July 2018. The awareness and prevalence of PPIUCD was assessed. At 6 week follow-up visit, women with PPIUCD were asked for symptoms of unusual vaginal discharge, irregular or heavy bleeding per vagina, and any expulsions if noticed. All the data was recorded and assessed.

Results: Out of 1478 deliveries, 1372 were eligible for PPIUCD. 335 patients got PPIUCD inserted. 295 patients were followed as 40 patients were lost to follow up. $79.3 \%$ women did not have any complaints. $11.8 \%, 1 \%$ and $7.4 \%$ women had only heavy menstrual bleeding, only lower abdominal pain and both symptoms respectively. Spontaneous expulsion rate was noted in one patient $(0.3 \%)$ at 6 weeks. IUCD removal was done in 4 patients who had complaints of pain and heavy menstrual bleeding not conservatively managed.

Conclusions: PPIUCD insertion is a safe, convenient and effective method of contraception. The benefits of contraception immediately after delivery outweigh disadvantage of complications. Antenatal counseling and follow up in hospitals need to be strengthened to increase awareness and acceptability of PPIUCD.
\end{abstract}

Keywords: Copper T, Contraception, Intrauterine device, Postpartum

\section{INTRODUCTION}

NFHS-4 survey (2015-16), in India revealed that contraceptive prevalence rate is $56.3 \%$. The prevalence of intrauterine device among the contraceptive users is $1.7 \% .^{1}$

With consistent increase in unwanted pregnancies in India, there is a need for surveillance over number of contraceptive users and type of contraceptive used. Intrauterine copper device's (IUCD) are among the most commonly used long acting reversible method of contraception in women of reproductive age worldwide, which reverts fertility quickly as soon as withdrawn. Copper IUCDs are the most commonly used type of IUCD and the $\mathrm{Cu} \mathrm{T} 380 \mathrm{~A}$ has been found to be most effective IUCD. ${ }^{2}$

Insertion of IUCD in postpartum period has advantages of safety due to blunt insertion technique, and certainty of non-pregnancy of woman apart from simplicity, minimal motivation, and reversibility, free of cost availability, virtually no systemic side effects and high continuation rate. ${ }^{3}$ 
Our study aims to determine the prevalence of PPIUCD in a tertiary care facility and also study the awareness about the same and follow up care.

\section{METHODS}

This is a prospective observational study conducted in the antenatal ward of Department of Obstetrics and Gynecology of Dr. Ram Manohar Lohia Hospital, New Delhi, India from the period of July 2017 to July 2018. All antenatal patients who got CuT insertion done postpartum either after vaginal delivery or cesarean section were asked a prior prepared questionnaire. Demographic data was recorded which included age, religion, parity, mode of delivery. All patients were counseled for $\mathrm{CuT}$ as a contraceptive device during their visits to the hospital. The patients were asked when the first interaction with their physician regarding the PPIUCD was. It was recorded, either as ante-partum, intra-partum or immediate post partum period. They were also asked whether they were self aware of the PPIUCD or were informed by healthcare worker. All patients were advised for follow up after 6 weeks post partum. The time when the patients reported for follow was documented. The patients were asked for complaints such as unusual vaginal discharge, irregular or heavy bleeding per vagina, and were also asked for any expulsion if noted. Patients who did not visit the hospital for follow up were called and asked for any complication telephonically. All data was recorded in Microsoft excel and was analyzed.

Those who were known case of STI/RTI and had a history of medical diseases like heart disease, sickle cell disease, jaundice or known case of intramural/submucosal fibroid or congenital malformation of uterus were excluded from the study. Women having hemoglobin $<8 \mathrm{gm} \%$, rupture of membranes more than 18 hours, obstructed labor, significant postpartum hemorrhage, coagulation disorders were excluded from the study.

\section{RESULTS}

A total of 1478 females were delivered in the labor room/ OT under the Department of Obstetrics and Gynecology of Dr. Ram Manohar Lohia Hospital, New delhi, India from July 2017 to July 2018. 106 patients were excluded as per the exclusion criteria. Thus, out of remaining 1372 females delivered, 335 patients used copper $\mathrm{T}$ as a contraceptive device, rendering $24.4 \%$ prevalence of PPIUCD insertion as illustrated in Figure 1.

Mean age in this study was 27.53 years as mentioned in Table 1. Maximum cases were between 21-30 years of age group (77\%). Authors observed 43\% (110) patients with PPIUCD had parity as 1. Among all 335 patients who got PPIUCD, $198(59.1 \%)$ of patients delivered vaginally and $137(40.9 \%)$ of patients were delivered by caesarean section. $283(84 \%)$ patients were counselled by health care provider and only $52(16 \%)$ were self motivated for copper $\mathrm{t}$ insertion. Only 137 (40.9\%) patients had the first interaction with healthcare worker regarding PPIUCD during antenatal period. Remaining $62(18.5 \%)$ and $136(40.6 \%)$ patients were counselled during labor and immediate post partum period for the first time respectively.

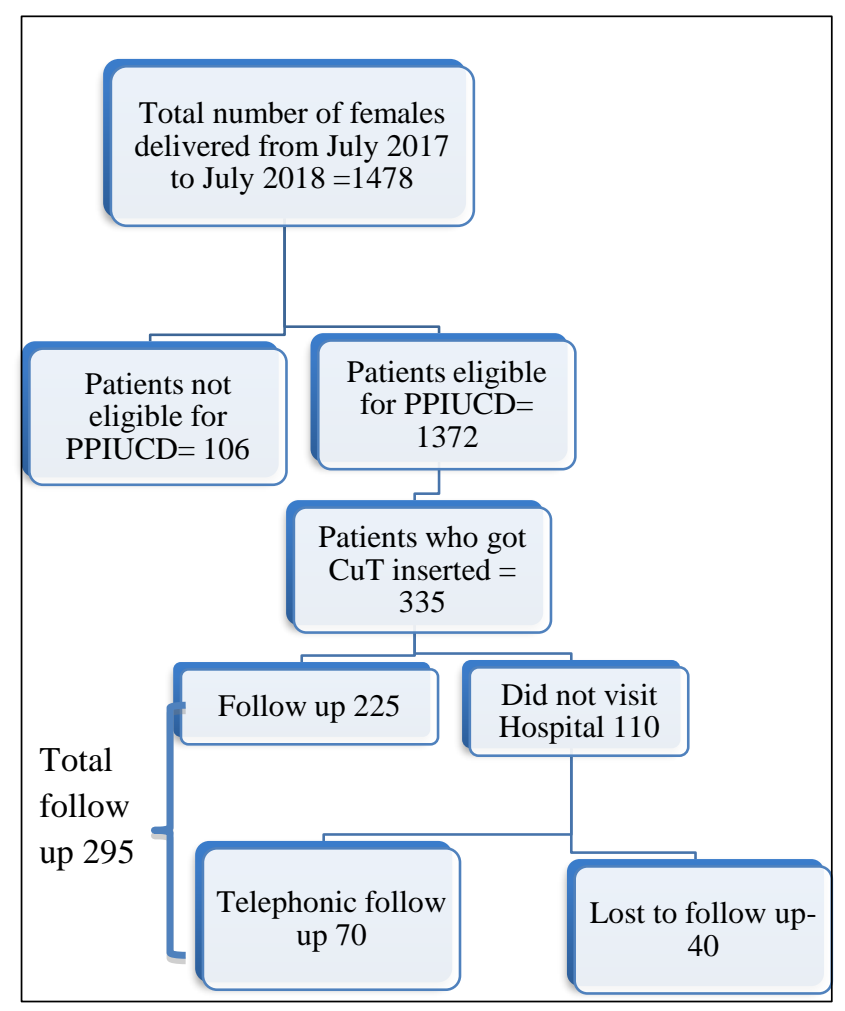

Figure 1: Prevalence and follow up.

All patients were advised for a follow up at 6 weeks postpartum. 20 patients $(6 \%)$ followed up prior to 6 weeks. 185 patients $(55 \%)$ followed up at 6 weeks post partum period. 110 (33\%) did not follow up during the entire study period. Despite telephonic follow up from hospital no data was available on follow up care for 40 $(\sim 12 \%)$ patients. The complications are enlisted in Table 2. $234(79.3 \%)$ patients did not have any complaints during the follow up care. 35 (11.8\%) patients had complaint of excessive bleeding. All except one patient $(0.3 \%)$ did not respond to tranxemic acid as a treatment for excessive bleeding for which the copper $\mathrm{t}$ was removed during the follow up visits. $3(\sim 1 \%)$ patients had complained of only lower abdominal pain as a symptom during the follow up care, one of which had got copper $t$ removal done outside the hospital, 2 patients responded to conservative management (NSAIDs and KIT-6).

One patient $(0.3 \%)$ had spontaneous expulsion of $\mathrm{Cu} \mathrm{T}$ during the follow up. $22(7.4 \%)$ patients had complaints of both excessive bleeding and pain lower abdomen among which $2(0.7 \%)$ patients did not respond to conservative management and thus needed copper $\mathrm{t}$ removal. Overall $5(1.6 \%)$ had copper $\mathrm{t}$ removed including 1 spontaneous expulsion. 
Table 1: Demographics and awareness.

\begin{tabular}{|c|c|c|}
\hline Parameters & Number of patients & Percentage \\
\hline \multicolumn{3}{|c|}{ Age group (years) } \\
\hline $11-20$ & 11 & $3 \%$ \\
\hline $21-30$ & 257 & $77 \%$ \\
\hline$>30$ & 67 & $20 \%$ \\
\hline \multicolumn{3}{|l|}{ Religion } \\
\hline Hindu & 302 & $90 \%$ \\
\hline Muslim & 31 & $9 \%$ \\
\hline Christian & 2 & $1 \%$ \\
\hline \multicolumn{3}{|l|}{ Parity } \\
\hline 3 & 56 & $17 \%$ \\
\hline 2 & 143 & $42 \%$ \\
\hline 4 & 19 & $6 \%$ \\
\hline 5 & 3 & $1 \%$ \\
\hline 6 & 4 & $1 \%$ \\
\hline 1 & 110 & $33 \%$ \\
\hline \multicolumn{3}{|c|}{ Mode of delivery } \\
\hline LSCS & 137 & $40.90 \%$ \\
\hline NVD & 198 & $59.10 \%$ \\
\hline \multicolumn{3}{|c|}{ Counselled By- } \\
\hline $\begin{array}{l}\text { Healthcare } \\
\text { worker }\end{array}$ & 283 & $84 \%$ \\
\hline Self & 52 & $16 \%$ \\
\hline \multicolumn{3}{|c|}{ Counseling period } \\
\hline Antenatal & 137 & $40.9 \%$ \\
\hline During labor & 62 & $18.5 \%$ \\
\hline Post partum & 136 & $40.6 \%$ \\
\hline \multicolumn{3}{|c|}{ Duration of follow up visit } \\
\hline 10 weeks & 15 & $4 \%$ \\
\hline 12 weeks & 5 & $1 \%$ \\
\hline 4 weeks & 9 & $3 \%$ \\
\hline 5 weeks & 11 & $3 \%$ \\
\hline 6 weeks & 185 & $55 \%$ \\
\hline No follow up & 110 & $33 \%$ \\
\hline Untraceable & 40 & $11.9 \%$ \\
\hline Grand total & 335 & \\
\hline
\end{tabular}

\section{DISCUSSION}

In the present observational study, the prevalence of PPIUCD over a period of 1 year in a tertiary care center is $24.4 \%$, which is similar to another study $(21.77 \%)$ conducted in Bundelkhand region in Aug 2018 by Rajni et al. ${ }^{4}$

In present study majority of women were in age group of 21-30 years (77\%) who accepted copper $\mathrm{T}$ as contraceptive, which is in contrast to Kanhere AV et al, where $88.5 \%$ patients who were counseled in age group of 20-29 years, only 35\% (62 women) patients accepted the copper $\mathrm{T}$ insertion post partum. ${ }^{5}$ In another study Agarwal $\mathrm{N}$ et al, $94.3 \%$ women who were counseled among the age group of 20-29 years, $91.7 \%$ had copper $\mathrm{t}$ insertion done post partum. ${ }^{6}$
In this study, 33\% (110 patients) were primipara and $67 \%$ (225 patients) were multipara, which differs from study conducted by Ranjana et al where $41 \%$ of patients were primipara and $58.82 \%$ were multiparous. ${ }^{2}$ Both the studies were conducted in the same hospital at different time periods. This statistics highlights the possible decreasing usage of copper $\mathrm{T}$ as spacing contraceptive among primipara. ${ }^{8}$

Table 2: Complications and management.

\begin{tabular}{|l|l|l|}
\hline Complications & $\begin{array}{l}\text { No. of } \\
\text { patients }\end{array}$ & $\%$ \\
\hline No complaints & 234 & $79.3 \%$ \\
\hline Bleeding & 35 & $11.8 \%$ \\
\hline $\begin{array}{l}\text { Not responded to tranexa- } \\
\text { removed }\end{array}$ & 1 & $0.3 \%$ \\
\hline Responded to tranexa & 34 & $11.5 \%$ \\
\hline Bleeding and pain & 22 & $7.4 \%$ \\
\hline $\begin{array}{l}\text { Not responded to tranexa and } \\
\text { meftal spas followed by Copper T } \\
\text { removal }\end{array}$ & 2 & $0.7 \%$ \\
\hline $\begin{array}{l}\text { Responded to tranexa and meftal } \\
\text { spas pain }\end{array}$ & 20 & $6.7 \%$ \\
\hline Spontaneous expulsion & 1 & $0.3 \%$ \\
\hline Pain & 3 & $\sim 1 \%$ \\
\hline Removed outside hospital & 1 & $0.3 \%$ \\
\hline Responded to meftal spas & 1 & $0.3 \%$ \\
\hline Treated with KIT 6 & 1 & $0.3 \%$ \\
\hline Grand total & 295 & \\
\hline
\end{tabular}

Among 335 patients who got $\mathrm{Cu} \mathrm{T}$ inserted, 137 patients (40.9\%) were delivered by LSCS and 198 (59.1\%) patients were delivered by normal vaginal delivery.

Only $40.9 \%$ of patients were counseled in the antenatal period, remaining $59.1 \%$ patients were counseled either during labor or post partum. Antenatal period counseling holds importance as the doubts and myths about copper $\mathrm{T}$ can be cleared with the health care worker during routine antenatal OPD visits. A study by Neelima et al, and Hardik V et al, in 2015 and 2017 respectively highlights the importance of antenatal counseling for PPIUCD. ${ }^{9,10}$ Only 52 patients $(16 \%)$ in our study were aware of copper $\mathrm{T}$ prior to counseling by healthcare worker. Thus, there is a need to increase awareness of the same at social level, which can be done by proper implementation of different government programs.

In our study 110 patients (33\%) patients did not visit the hospital for follow up. Among them, 70 patients were contacted telephonically and by recall method were asked for any complaints. Remaining 40 patients (11.9\%) were lost to follow up.

Thus, the follow up of patients needs to be strengthened at root level to decrease unwanted pregnancies in post partum period, which could lead to anemia in mother, risk of scar dehiscence in cases of LSCS. 
234 patients $(79.3 \%)$ did not have any complaints, which is higher than study conducted by Ranjana et al where $58.47 \%$ had no complaints and similar to study conducted by Rajni et al where $62 \%$ of patients were satisfied with PPIUCD. ${ }^{2,4}$ Other studies using CuT-380 A have reported IUCD removal due to bleeding/pain as $6 \%$ to $8 \% .9,10$ Difference in types of IUCD could possibly explain the different rates of bleeding problem, where as we observed approximately $1 \%$ removal for the same reasons.

\section{CONCLUSION}

Copper $\mathrm{T}$ is a safe method of contraception in the post partum period. The complications such as bleeding and pain usually respond to medical management. There needs to be a strong antenatal counseling for every patient by the healthcare worker to increase acceptability. The follow up of the patients with PPIUCD also needs to be strengthened so as to correct the complications of patients.

\section{ACKNOWLEDGMENTS}

Authors would like to thank Department of Obstetrics and Gynecology, Dr. Ram Manohar Lohia Hospital and PGIMER, New Delhi, India.

Funding: No funding sources Conflict of interest: None declared

Ethical approval: The study was approved by the Institutional Ethics Committee

\section{REFERENCES}

1. National Family Health Survey. NFHS-4 fact sheets for key indicators based on final data, 2015-16. Available at; http://www.rchiips.org/NFHS/factsheet_NFHS4.shtml.

2. Ranjana, Verma A, Chawla I. A follow up study of postpartum intrauterine device insertion in a tertiary health care centre. Int J Reprod Contracept Obstet Gynecol. 2017;6:2800-5.
3. Katheit G, Agarwal J. Evaluation of post-placental intrauterine device (PPIUCD) in terms of awareness, acceptance, and expulsion in a tertiary care centre. Int J Reprod Contracept Obstet Gynecol. 2013;2:539-43.

4. Gautam R, Arya KN, Kharakwal S, Singh S, Trivedi M. Overview of immediate PPIUCD application in Bundelkhand Region. J Evolut Med Dent Sci. 2014;3(36):9518-26.

5. Kanhere AV, Pateriya P, Jain M. Acceptability and feasibility of immediate postpartum IUCD insertion in a tertiary care centre in Central India. Int J Reprod Contracep Obstet Gynecol. 2015;4(1):179-84.

6. Agarwal N, Gupta M, Sharma A, Arora R. Antenatal counselling as a tool to increase acceptability of postpartum intrauterine contraceptive device insertion in a tertiary care hospital. Int $\mathbf{J}$ Reprod Contracept Obstet Gynecol. 2015;4(4):1137-41.

7. Agarwal N, Gupta M, Sharma A, Arora R. Antenatal counselling as a tool to increase acceptability of postpartum intrauterine contraceptive device insertion in a tertiary care hospital. Int $\mathbf{J}$ Reprod Contracept Obstet Gynecol. 2015;4:1137-41.

8. Hardik V, Khushbu P, Maitri S, Niyati P. Analysing barriers in acceptance of postpartum intrauterine device (PPIUCD) at tertiary care hospital of Gujarat. Natl J Integr Res Med. 2017;8(5):9-12.

9. Kittur S, Kabadi YM. Enhancing contraceptive usage by post-placental intrauterine contraceptive devices (PPIUCD) insertion with evaluation of safety, efficacy, and expulsion. IJRCOG. 2016;1(1):26-32.

10. Çelen Ş, Sucak A, Yıldız Y, Danışman N. Immediate postplacental insertion of an intrauterine contraceptive device during cesarean section. Contraception. 2011;84(3):240-3.

Cite this article as: Garg N, Sarkar B, Singla S, Meena RK. Demographics and follow up of post partum intra-uterine copper device in tertiary hospital in Delhi, India. Int J Reprod Contracept Obstet Gynecol 2019;8:2232-5. 